OPEN ACCESS

Edited by:

Rafael Franco,

University of Barcelona, Spain

Reviewed by:

Maite Solas,

Universidad de Navarra, Spain Ana María Sanchez-Perez,

Jaume I University, Spain

${ }^{*}$ Correspondence:

Qihai Gong

gqh@zmc.edu.cn

Specialty section:

This article was submitted to

Neuropharmacology,

a section of the journal

Frontiers in Pharmacology

Received: 23 September 2016 Accepted: 18 January 2017

Published: 02 February 2017

Citation:

Deng Y, Long L, Wang K, Zhou J,

Zeng L, He L and Gong Q (2017) Icariside II, a Broad-Spectrum Anti-cancer Agent, Reverses

Beta-Amyloid-Induced Cognitive Impairment through Reducing Inflammation and Apoptosis in Rats.

Front. Pharmacol. 8:39.

doi: 10.3389/fphar.2017.00039

\section{Icariside II, a Broad-Spectrum Anti-cancer Agent, Reverses Beta-Amyloid-Induced Cognitive Impairment through Reducing Inflammation and Apoptosis in Rats}

\author{
Yuanyuan Deng ${ }^{1}$, Long Long ${ }^{2}$, Keke Wang ${ }^{3}$, Jiayin Zhou ${ }^{1}$, Lingrong Zeng ${ }^{1}$, Lianzi He ${ }^{1}$ \\ and Qihai Gong ${ }^{1 *}$
}

1 Department of Pharmacology, Key Laboratory of Basic Pharmacology of Ministry of Education, Zunyi Medical University, Guizhou, China, ${ }^{2}$ Department of Pharmacy, Zunyi Medical University, Guizhou, China, ${ }^{3}$ Zunyi Medical and Pharmaceutical College, Guizhou, China

Beta-amyloid $(A \beta)$ deposition, associated neuronal apoptosis and neuroinflammation are considered as the important factors which lead to cognitive deficits in Alzheimer's disease (AD). Icariside II (ICS II), an active flavonoid compound derived from Epimedium brevicornum Maxim, has been extensively used to treat erectile dysfunction, osteoporosis and dementia in traditional Chinese medicine. Recently, ICS II attracts great interest due to its broad-spectrum anti-cancer property. ICS II shows an antiinflammatory potential both in cancer treatment and cerebral ischemia-reperfusion. It is not yet clear whether the anti-inflammatory effect of ICS II could delay progression of AD. Therefore, the current study aimed to investigate the effects of ICS II on the behavioral deficits, $A \beta$ levels, neuroinflammatory responses and apoptosis in $A \beta_{25-35-}$ treated rats. We found that bilateral hippocampal injection of $A \beta_{25-35}$ induced cognitive impairment, neuronal damage, along with increase of $A \beta$, inflammation and apoptosis in hippocampus of rats. However, treatment with ICS II $20 \mathrm{mg} / \mathrm{kg}$ could improve the cognitive deficits, ameliorate neuronal death, and reduce the levels of $A \beta$ in the hippocampus. Furthermore, ICS II could suppress microglial and astrocytic activation, inhibit expression of IL-1 $\beta$, TNF- $\alpha$, COX-2, and iNOS mRNA and protein, and attenuate the $A \beta$ induced $\mathrm{Bax} / \mathrm{Bcl}-2$ ratio elevation and caspase- 3 activation. In conclusion, these results showed that ICS II could reverse A $\beta$-induced cognitive deficits, possibly via the inhibition of neuroinflammation and apoptosis, which suggested a potential protective effect of ICS II on AD.

Keywords: Alzheimer's disease, ICS II, beta-amyloid, neuroinflammation, apoptosis

\footnotetext{
Abbreviations: $\mathrm{AD}$, Alzheimer's disease; $\mathrm{ANOVA}$, analysis of variance; $\mathrm{A} \beta$, beta-amyloid; $\mathrm{BCA}$, bicinchoninic acid; $\mathrm{COX}-2$, cyclooxygenase-2; GFAP, glial fibrillary acidic protein; HE, hematoxylin-eosin; IBA-1, ionize calcium-binding adapter molecule 1; ICS II, Icariside II; IL-1 $\beta$, interleukin-1 $\beta$; iNOS, inducible nitric oxide synthase; MWM, Morris water maze; NS, normal saline; OD, optical density; PBS, phosphate buffered saline; TNF- $\alpha$, tumor necrosis factor; TUNEL, TdT-mediated dUTP nick end labeling.
} 


\section{INTRODUCTION}

Alzheimer's disease, with impairment in memory and cognition as the main clinical manifestation, has become a considerable social and medical burden for causing chronic disability and high mortality among elders (Joan et al., 2013; Alzheimer's Association, 2015). Growing evidences show that the overproduction and accumulation of neurotoxic $\beta$-amyloid peptide $(A \beta)$ in the brain is the primary cause driving $A D$ pathogenesis (Barnabas James, 1997; Suh and Checler, 2002; Gouras et al., 2014). While the underlying mechanisms of $\mathrm{A} \beta$-induced neuronal death in $\mathrm{AD}$ remain unclear, accumulating studies suggest that neuroinflammation and apoptosis may be a consequence of the neurotoxic $A \beta$ accumulation and may play a role in $\mathrm{AD}$ progression and pathology (Bamberger and Landreth, 2002; Paula et al., 2010). Moreover, novel agents targeting apoptosis suppression and/or inflammatory inhibition can slow the progression of cognitive dysfunction and/or accumulation of $A \beta$ in animal models (Townsend and Domenico, 2005; Wang et al., 2012). However, the existing anti-inflammatory agents such as non-steroidal anti-inflammatory drugs (NSAIDs) have generated mixed results (Breitner et al., 2009; Potter, 2010). Thus, it is an imperative to develop new and alternative antiinflammatory and/or anti-apoptosis therapies to be used for $\mathrm{AD}$ treatment.

Herba Epimedii (Epimedium brevicornum Maxim, Yinyanghuo in China), a traditional Chinese herbal medicine, has been widely used in East Asia for the treatment of cardiovascular disease, osteoporosis, erectile dysfunction and dementia (Xiao et al., 1993; Meng et al., 2005; Sze et al., 2010). ICS II, a flavonoid isolated from Epimedii herb, has been shown to possess a wide range of pharmacological effects on anti-tumor, anti-oxidation and anti-osteoporosis. Recently, ICS II has gain increasing interests in its anti-cancer properties, and in vitro and in vivo studies suggest ICS II displayed activity against lung carcinoma, prostate cancer, melanoma and breast cancer (Lee et al., 2009; Song et al., 2012; Wu et al., 2015). Common signaling pathways and therapeutic targets relating cancer and neurodegenerative diseases have been increasingly reported (Plunfavreau et al., 2010; Driver, 2012). A recent study showed that the anti-cancer mechanism of ICS II is its suppressive effects of pro-inflammatory cytokines in inflammatory microenvironment (Jie et al., 2016). Inflammation is a hallmark of cancer and various central nervous system disorders. Our research group and other teams have recently shown that ICS II has neuroprotective effects during cerebral ischemia-reperfusion via inflammatory inhibition and apoptosis suppression (Yan et al., 2014; Deng et al., 2016). It is implied that ICS II as an anti-inflammation agent could be potentially used to ameliorate neurodegenerative diseases. However, whether ICS II exerts protective effects on AD is still unknown.

The present study was designed to investigate whether ICS II treatment ameliorates cognitive deficits induced by hippocampal $A \beta_{25-35}$ injection in rats. Furthermore, inflammatory responses and neuronal apoptosis were explored to elucidate the possible mechanisms underlying the protective effect of ICS II on AD.

\section{MATERIALS AND METHODS}

\section{Drugs and Chemicals}

Icariside II (purity $\geq 98 \%$ by HPLC), purchased from Nanjing Zelang Medical Technology Corporation Ltd. (Nanjing, China), and dissolved in NS. $A \beta_{25-35}$ was purchased from SigmaAldrich (St. Louis, MO, USA), dissolved in sterilized NS at the concentration of $2 \mu \mathrm{g} / \mu \mathrm{L}$, and then incubated at $37^{\circ} \mathrm{C}$ for 7 days before injection to make the state of aggregation (Pike et al., 1995; Nie et al., 2010).

\section{Animals}

Sixty adult male Sprague-Dawley rats (3 months old, 250 to 280 g) were provided by the Experimental Animal Center of Third Military Medical University (SPF-grade, Certificate NO. SCXK 2007-0005). Rats were group housed in SPFgrade weather-controlled animal facilities (certificate NO. SYXK 2011-004) (room temperature was maintained at $23 \pm 1^{\circ} \mathrm{C}$ ), relative humidity at $60 \%$, and $12 \mathrm{~h}$-light/ $12 \mathrm{~h}$-dark cycle was applied). Animal experiments were performed according the State Committee of Science and Technology of the People's Republic of China Order No. 2 on November 14, 1988 (revised in 2011), and the study protocol was approved by the Experimental Animal Ethics Committee of the Zunyi Medical University. All efforts were made to minimize animal use and animal suffering.

\section{Surgery and Drug Administration}

The rats were randomly divided into the following four groups ( $n=15$ for each group): sham group, sham + ICS II group, $A \beta$ group, and $A \beta+$ ICS II group, respectively. The $\mathrm{A} \beta$-induced cognitive impairment in rats was established as previously described (Nie et al., 2010). Briefly, standard aseptic skull drilling procedure was employed in rats after i.p. chloral hydrate $(300 \mathrm{mg} / \mathrm{kg})$ anesthesia. Rats then received bilateral hippocampal injection of $5 \mu \mathrm{L} \mathrm{A} \beta_{25-35}(2 \mu \mathrm{g} / \mu \mathrm{L})$ or $5 \mu \mathrm{L}$ sterilized NS at the following coordinates: front/rear $-3.3 \mathrm{~mm}$, medial/lateral $\pm 2.0 \mathrm{~mm}$ relative to bregma, and dorsal/ventral $3.6 \mathrm{~mm}$ below dura. The injection was carried out slowly at a rate of $1 \mu \mathrm{L} / \mathrm{min}$ and left for another $5 \mathrm{~min}$ after injection to minimize reflux along the injection track. Sham-operated animals received the same surgery with the exception that sterilized NS was administrated instead of $A \beta_{25-35}$. Rats then received intragastrically administration of ICS II $20 \mathrm{mg} / \mathrm{kg}$ when fully awake after surgery, once a day for 15 days or the volumematched saline according to their group assignments as described above.

\section{Morris Water Maze}

The MWM task was used to assess spatial learning and memory as previously described (Vorhees and Williams, 2005; Gong et al., 2010). Trials were carried out during days 11-15 after the infusion of $A \beta_{25-35}$. The task was conducted in a fixed circular tank (diameter of $120 \mathrm{~cm}$ and height of $50 \mathrm{~cm}$ ), filled with a depth of $30 \mathrm{~cm}$ water $\left(23 \pm 1^{\circ} \mathrm{C}\right)$. Rats were trained to find a clear Perspex platform hidden by arranging its top surface (diameter: $10 \mathrm{~cm}) 1 \mathrm{~cm}$ below the water. The pool was divided into four 
quadrants with four start positions. The task consisted of two steps. The first step was the place navigation test conducted twice daily for 4 consecutive days, during which the escape latency and the swimming speed were recorded. The animals were allowed $120 \mathrm{~s}$ to find the platform and then allowed to remain on the platform for $20 \mathrm{~s}$. If a rat failed to reach the platform within $120 \mathrm{~s}$, it was manually guided to the platform, and remained for $20 \mathrm{~s}$. In this case, its escape latency was marked as $120 \mathrm{~s}$. The second step was run on the 5 th day as the spatial probe test without the platform to evaluate the final strength of the memory traces.

\section{Tissue Preparation}

On day 15 after the behavioral tests, animals were anesthetized with $7 \%$ chloral hydrate and perfused with $0.1 \mathrm{M}$ PBS. The brains were immediately removed and divided into left and right hemispheres. One hemisphere was fixed in 4\% paraformaldehyde for 1 week, and then embedded in paraffin. The other hemisphere separated the hippocampus and stored the hippocampus at $-80^{\circ} \mathrm{C}$ until analysis.

\section{Hematoxylin and Eosin Staining, NissI Staining}

Embedded brain tissue sections were coronally cut $(4 \mu \mathrm{m})$ using a Leica slicing machine for $\mathrm{HE}$ staining ( $\mathrm{Li}$ et al., 2015) and Nissl staining (Liu et al., 2015), respectively. The histopathological abnormalities were observed under an optical microscope (KS300, Zeiss-Kontron, Germany).

\section{TUNEL Assay}

TdT-mediated dUTP nick end labeling assay was performed to examine the cellular apoptosis according to the manufacturer's instructions using the in situ cell death detection kit-POD (Roche Diagnostics GmbH Co., Germany). TUNEL staining sections were viewed and counted by a light microscope (KS300, Zeiss-Kontron, Germany). Quantitation was performed by counting the number of positive cells in five randomly chosen fields from each group and the percentage of TUNELpositive cells was calculated according to this formula: \% TUNEL-positive cells $=($ TUNEL-positive neurons $($ brown $) /$ total neurons) $\times 100$.

\section{Immunohistochemical Staining}

The brain sections from each animal were microwaved for $5 \mathrm{~min}$, and then incubated with 3\% hydrogen peroxide in PBS for $20 \mathrm{~min}$ to quench the endogenous peroxidase activity. The samples were then blocked with $10 \%$ normal goat serum in PBS for $20 \mathrm{~min}$, and incubated with primary antibody against GFAP (1:500, Abcam, USA) and anti-IBA-1 (1:300, Abcam, USA) overnight at $4^{\circ} \mathrm{C}$. After washing with PBS three times, sections were incubated with biotinylated goat anti-rabbit or rabbit anti-goat IgG-horseradish peroxidase (HRP) (1:500, Beyotime, China) for $2 \mathrm{~h}$ and then incubated with avidin-biotin peroxidase complex (ImmunoPure ABC kit, Beyotime, China) for $90 \mathrm{~min}$ and visualized by a DAB kit (Boster, China).

Immunostained sections were imaged with an Olympus microscope (Olympus, Japan) and assessed using Image Pro Plus
6.0 software (Saur et al., 2014). Results were expressed as the average intensity of the positive immunoreactive cells of GFAP and IBA-1 immunohistochemistry and the average number of immunolabeled cells per $\mathrm{mm}^{2}$ in CA1 and dentate gyrus (DG) of the hippocampus. Three digitized images were obtained from each section, and three sections were taken from each animal for analysis. The images were converted to 8-bit gray scales to measure the regional OD and areas of interest (AOIs).

\section{Quantitative Real-Time PCR}

Gene expression of interleukin-1 beta (IL-1 $\beta$ ), COX-2, TNF- $\alpha$ and iNOS was detected by real time RT-PCR. Total RNA of hippocampus was extracted using Trizol reagent (Takara Bio Co., China). The primer sequences of the selected genes were designed by the Primer 3 software and listed in Table 1. Reverse transcription was undertaken using MuLV reverse transcriptase and Oligo-dT primers (Takara Bio Co., China). Real-time PCR analysis was performed with the SYBR green PCR Master Mix (Takara Bio Co., China). The relative expression levels of the genes were quantified as cycle time $(\mathrm{Ct})$ values normalized with GAPDH of the same sample.

\section{Western Blot Analysis}

The protein expression of $\mathrm{A} \beta_{1-40}, \mathrm{COX}-2$, iNOS, TNF- $\alpha$, IL$1 \beta$, Bax, Bcl-2, and caspase-3 was analyzed using Western blot. Hippocampus were removed from the brain hemispheres and homogenized in radioimmunoassay lysis buffer containing protease inhibitors. The homogenized samples were centrifuged for $15 \mathrm{~min}$ at $12,000 \mathrm{~g}$ and $4^{\circ} \mathrm{C}$. Protein concentrations from each sample were determined using the BCA protein assay kit (Biocolor Biotechnology, China). $50 \mu \mathrm{g}$ protein of each sample was heated at $100^{\circ} \mathrm{C}$ for $5 \mathrm{~min}$, and then separated by SDS-PAGE and transferred onto a PVDF membrane. The membrane was blocked with 5\% non-fat milk in PBS buffer for $2 \mathrm{~h}$, and then incubated with primary antibodies against $A \beta_{1-40}$ (1:1,000, Abcam, USA), IL-1 $\beta$ (1:1,000, Abcam, USA), COX-2 (1:1,000, Abcam, USA), TNF- $\alpha$ (1:1,000, Abcam, USA), iNOS (1:1,000, Abcam, USA), Bax (1:1,000, Abcam, USA), Bcl-2 (1:1,000, Abcam, USA), active + pro caspase-3 (1:1,000, Abcam, USA) and $\beta$-actin (1:2,000, Beyotime, China) at $4^{\circ} \mathrm{C}$ overnight, followed by horseradish peroxidase conjugated secondary antibodies (1:2,000, Beyotime, China) incubation.

\begin{tabular}{|c|c|c|c|}
\hline Gene & $\begin{array}{c}\text { GeneBank } \\
\text { access }\end{array}$ & Forward & Reverse \\
\hline TNF- $\alpha$ & NM_012675.3 & $\begin{array}{l}\text { TCAGTTCCA } \\
\text { TGGCCCAGAC }\end{array}$ & $\begin{array}{l}\text { GTTGTCTITGA } \\
\text { GATCCATGCCT }\end{array}$ \\
\hline $\mathrm{IL}-1 \beta$ & NM_031512.2 & $\begin{array}{l}\text { GCTGTGGCAGCT } \\
\text { ACCTATGTCTTG }\end{array}$ & $\begin{array}{l}\text { AGGTCGTCATC } \\
\text { ATCCCACGAG }\end{array}$ \\
\hline cox-2 & NM_017232.3 & $\begin{array}{l}\text { AACACGGACTTG } \\
\text { CTCACTITTTG }\end{array}$ & $\begin{array}{l}\text { AATGGAGGC } \\
\text { CTITGCCACTG }\end{array}$ \\
\hline iNOS & NM_012611.3 & $\begin{array}{l}\text { ACCTITATGT } \\
\text { TTGTGGCGATG }\end{array}$ & $\begin{array}{l}\text { TCAACCTGC } \\
\text { TCCTCACTCAA }\end{array}$ \\
\hline GAPDH & NM_017008.4 & $\begin{array}{l}\text { CAGTGCCAGC } \\
\text { CTCGTCTCA }\end{array}$ & $\begin{array}{l}\text { TAACCAGGCG } \\
\text { TCCGATACG }\end{array}$ \\
\hline
\end{tabular}



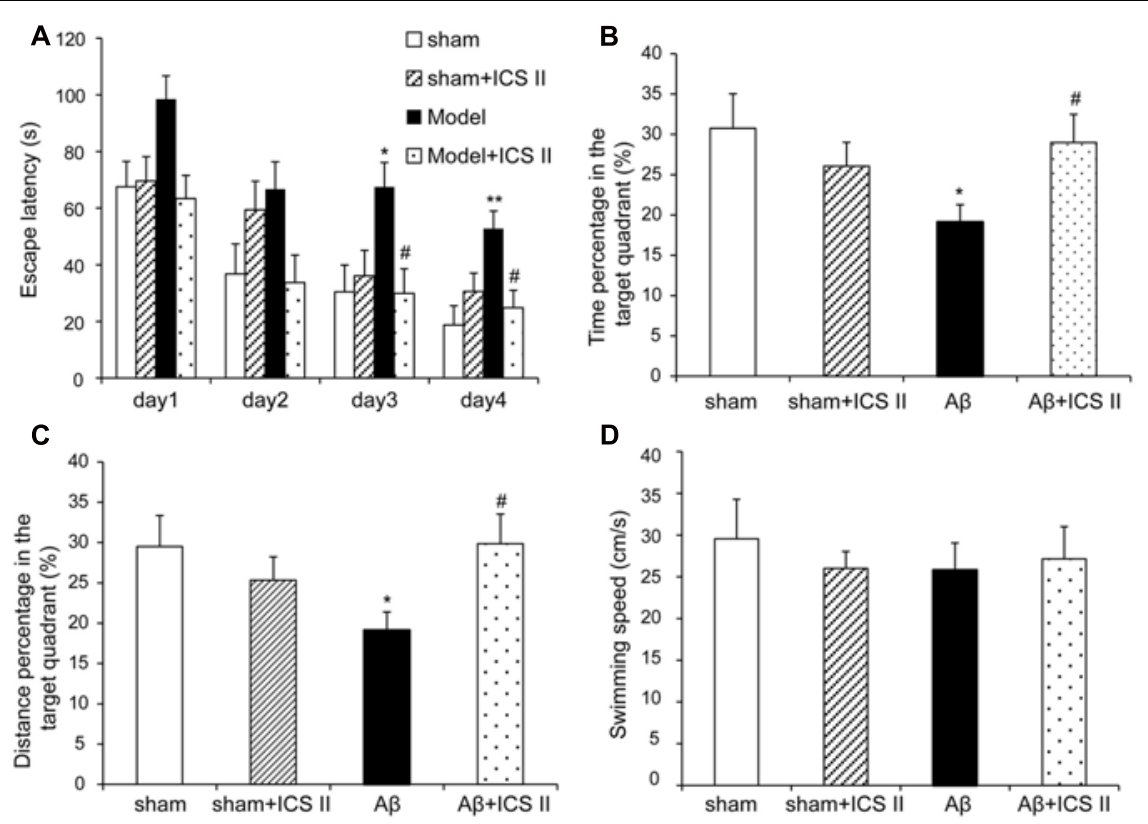

FIGURE 1 | Icariside II ameliorated $\mathbf{A} \boldsymbol{\beta}_{\mathbf{2 5}-\mathbf{3 5}}$-induced learning and memory impairments. Rats were slowly injected $A \beta_{25}-35$ or vehicle bilaterally into each lateral ventricle and then given 20 mg/kg ICS II for 15 days. Morris water maze was performed for 5 consecutive days from day 11 after surgery. (A) The escape latency of the rats to reach the hidden platform from days 1 to 4 . (B) The time spent in the target quadrant and the frequency crossing the target quadrant. (C) The percentage of the time spent in target quadrant on the 5th day. (D) The average swimming speed. Data were expressed as mean \pm SEM $(n=10 \sim 12) . * P<0.05$, ${ }^{* *} P<0.01$ vs. sham; ${ }^{*} P<0.05$ vs. A $\beta$ alone.

Immunoblots were visualized with chemiluminescence reagent BeyoECL Plus (Beyotime, China) and quantified with Quantity One software v4.52 (Bio-Rad).

\section{Statistics}

The data were presented as means \pm SEM. Water maze test data were analyzed using the repeated measures ANOVA and multivariate tests. Other data were analyzed using one-way ANOVA and followed by Bonferroni's multiple comparison tests with SPSS 19.0 software. $P<0.05$ was considered statistically significant.

\section{RESULTS}

\section{ICS II Alleviated A $\beta$-Induced Spatial Learning and Memory Impairment}

To investigate the effect of ICS II on the learning and memory deficits produced by $A \beta_{25-35}$ injection, spatial learning, and memory ability was examined using a 5-day MWM test from day 11 after surgery. As shown in Figure 1A, in the navigation test sham and sham + ICS II rats quickly reached the platform, while $\mathrm{A} \beta_{25-35}$ treated rats took a longer escape latency to arrive at the location of the hidden platform compared with the sham group starting from day $3[F(3,41)=4.165, P=0.012]$, indicating that the memory deficits could be induced by $A \beta_{25-35}$. Escape latency was significantly decreased in ICS II-treated rats compared with that of $A \beta_{25-35}$ group on days 3 and $4(P<0.05)$. In the spatial probe test, the time the animals spent in the target quadrant and target quadrant distance in $\mathrm{A} \beta$ group were lower than that in sham group $(P<0.05$, Figures $\mathbf{1 B}, \mathbf{C})$, indicative of cognitive impairments. However, ICS II significantly increased the time and distance that the $A \beta$-treated rats spent in target quadrant. Importantly, the swimming speed was no significantly different among these groups, suggesting the lack of motor function deficit (Figure 1D). Taken together, these data clearly indicated that ICS II improved $A \beta$-induced cognitive impairment in rats.

\section{ICS II Protected against Neuronal Loss and Apoptosis in $A \beta_{25-35}$-Treated Rats}

$\mathrm{A} \beta_{25-35}$-induced neuropathological changes, neuronal loss, and apoptosis were assessed by HE staining, Nissl staining and TUNEL assay, respectively. HE staining (Figure 2) showed that the neurons in the sham group had normal morphology and clear boundary, while most hippocampal neurons disappeared, were dark stained or lacking a visible cell boundary in the CA1 areas in the $A \beta_{25-35}$-treated rats compared with those of the sham rats. Moreover, treatment with $20 \mathrm{mg} / \mathrm{kg}$ ICS II markedly attenuated the $A \beta$-induced neuronal damage as evidenced by the fact that few unhealthy cells were observed in ICS II-treated group.

Nissl staining (Figure 3) showed highly dense pyramidal layer neurons with intact structure in the sham rats. In contrast, the number of neurons was lower and neurons appeared atrophied and pyknotic in the $A \beta$-treated group $[F(3,12)=20.803$, $P<0.001]$. Treatment with ICS II reduced the number of pyknotic and shrunken neurons compared with $A \beta$ alone group $(P<0.05)$. 


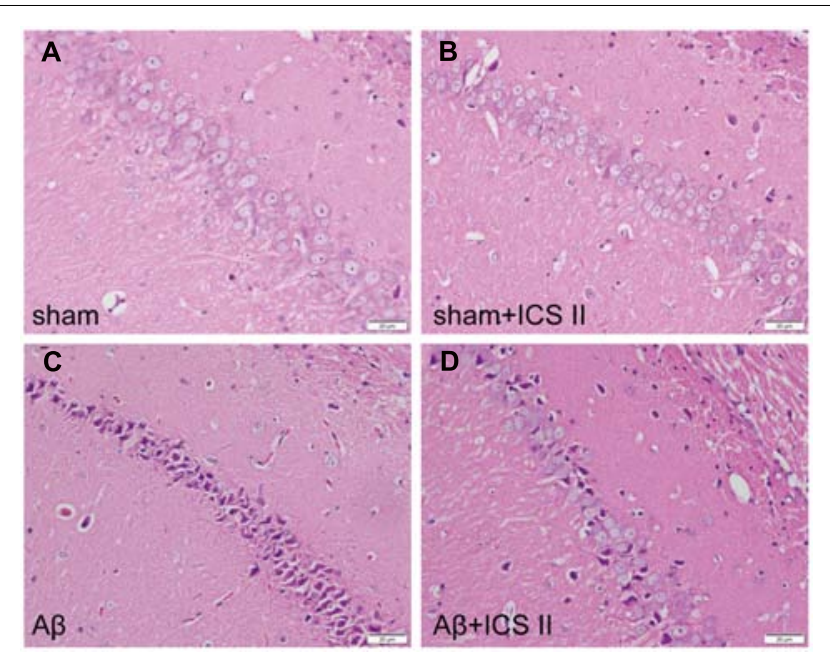

FIGURE 2 | Icariside II attenuated $A \beta_{25-35}$-induced morphological alterations in the hippocampus. (A-D) The sections of hippocampus CA1 region were obtained and stained with $\mathrm{HE}$ (magnification $400 \times$, scale bar $=20 \mu \mathrm{m})$.

TdT-mediated dUTP nick end labeling assay was performed to further assess the hippocampal neuronal apoptotic damage. Morphologically normal neurons were observed in the hippocampus of the rats in the sham group, suggestive of no TUNEL reaction (Figure 4). Rats in $A \beta$-treated group showed a significant number of TUNEL-stained cell nuclei in the CA1 region of the hippocampus compared with sham group $[F(3,12)=28.362, P<0.001]$, whereas $20 \mathrm{mg} / \mathrm{kg}$ ICS II significantly decreased the number of TUNELpositive neurons $(P<0.01)$. These results demonstrated that treatment with ICS II attenuated neuronal loss and apoptosis in the hippocampal CA1 region induced by $A \beta$ injection.

\section{ICS II Prevented A $\beta$ Levels in the Hippocampus of Rats}

Increased production and accumulation of amyloid protein is a key factor in the development of $\mathrm{AD}$ pathogenesis (Srivareerat et al., 2011). Contents of $A \beta_{1-40}$ were assessed using Western blot. As indicated in Figure 5, the protein levels of $\mathrm{A} \beta_{1-40}$ increased in $A \beta_{25-35}$-treated rats compared with those of sham group $[F(3,8)=40.084, P<0.001]$. However, treatment with ICS II prevented the increase in $\mathrm{A} \beta_{1-40}$ levels induced by $\mathrm{A} \beta_{25-35}$ $(P<0.01)$.

\section{ICS II Suppressed A $\beta$-Induced Astrocytes and Microglial Activation}

Hippocampal injection with $\mathrm{A} \beta$ triggers neuroinflammatory responses through the activation of inflammatory cells such as astrocytes and microglia (Diaz et al., 2012). To evaluate the astrocytic and microglia responses, immunohistochemistry staining was used to assess the expression of GFAP (astrocyte activation marker) and IBA-1 (microglia cell activation
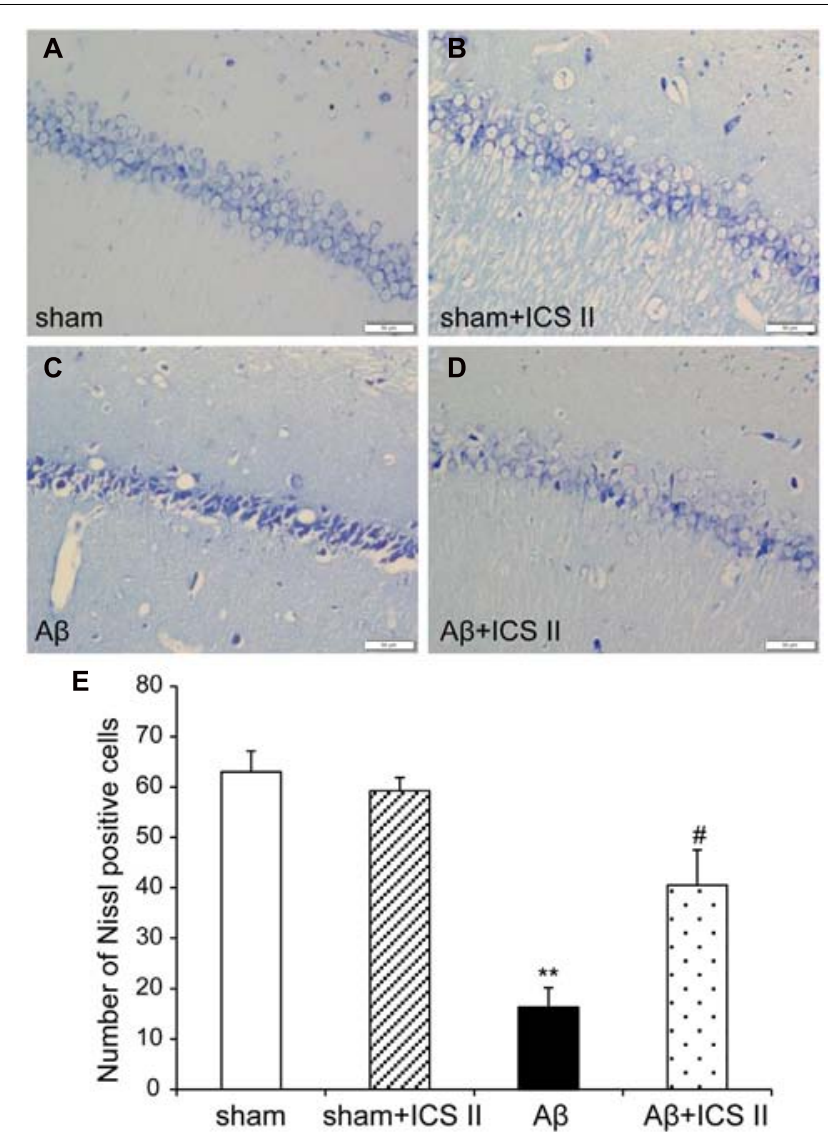

FIGURE 3 | Icariside II protected against $A \beta_{25-35}$-induced neuronal death in the hippocampus. (A-D) Nissl staining of hippocampus CA1 region sections (magnification 400×, scale bar $50 \mu \mathrm{m}$ ). (E) Quantitative analysis of Nissl bodies in the hippocampus CA1 region. Data were expressed as mean \pm SEM, $n=4$. ${ }^{* *} P<0.01$ vs. sham; ${ }^{\#} P<0.05$ vs. A $\beta$ alone.

marker). A significant increase in GFAP-positive staining in the hippocampal CA1 and DG regions from $A \beta$-induced rats was found as compared to sham group [the average intensity of GFAP-positive in the CA1 and DG regions: $F(3,12)=50.214$, $P<0.001 ; F(3,12)=31.752, P<0.001$; the number of astrocytes in the CA1 and DG regions: $F(3,12)=8.702, P<0.001$; $F(3,12)=20.484, P=0.002$, Figures 6A-C]. Importantly, both the average intensity of the positive immunoreactive cells and the number of astrocytes were decreased in the CA1 and DG regions of ICS II-treated A $\beta$ rats $(P<0.01$, $0.01,0.05,0.01$, respectively). IBA-1 immunostaining showed that injection of $\mathrm{A} \beta$ induced the activation of microglia cells as demonstrated by upregulation of IBA-1 expression and the presence of hypertrophic microglia with short thick processes, larger cell body volumes and fewer branches in $A \beta_{25-35}$-treated hippocampus than those in the sham group [the average intensity of IBA-positive in the CA1 and DG regions: $F(3,12)=11.618, P<0.001 ; F(3,12)=8.095$, $P=0.002$; the number of astrocytes in the CA1 and DG regions: $F(3,12)=6.365, P=0.006 ; F(3,12)=4.705, P=0.016$, Figures 6D-F). However, the number of IBA-immunoreactive 

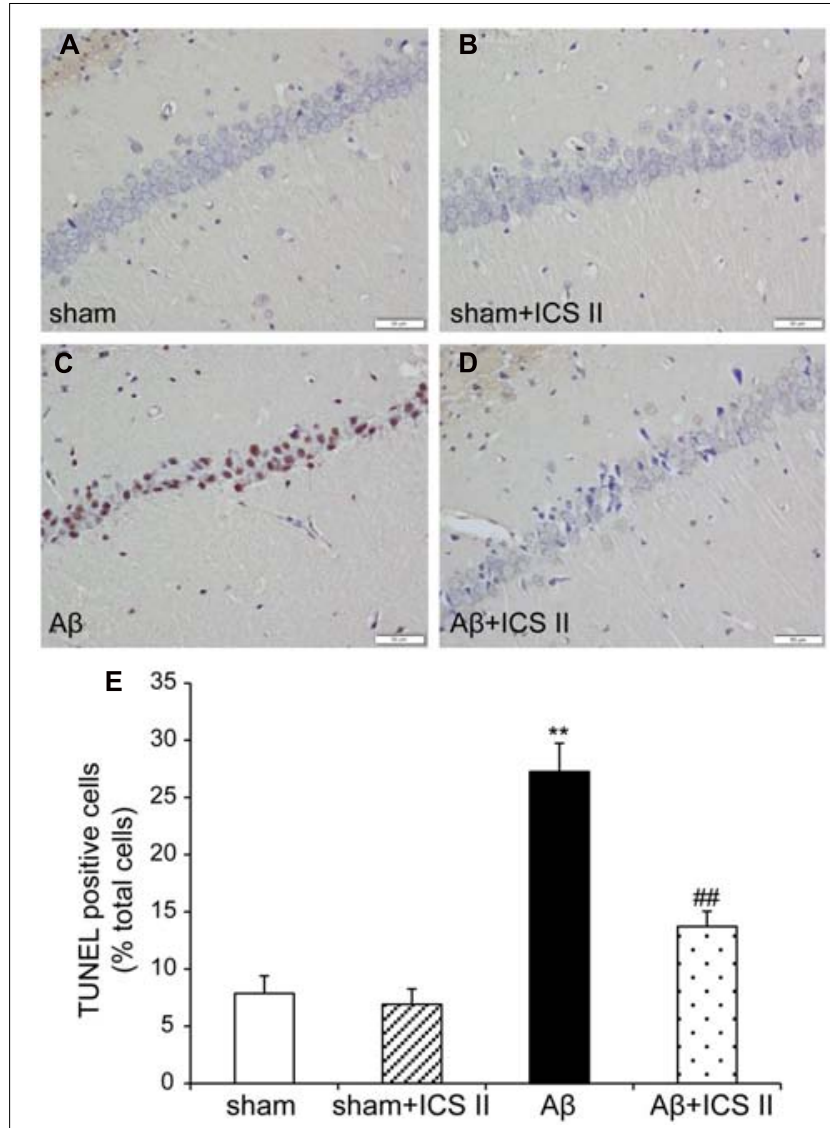

FIGURE 4 | Icariside II improved $A \beta_{25-35}$-induced neuronal apoptosis in the hippocampus. (A-D) TUNEL staining of hippocampus CA1 region sections (magnification $400 \times$, scale bar $50 \mu \mathrm{m}$ ) and (E) quantitative analysis of apoptotic cells in the hippocampus CA1 region. Data were expressed as mean \pm SEM, $n=4$. ${ }^{* *} P<0.01$ vs. sham; ${ }^{\# \# ~} P<0.01$ vs. A $\beta$ alone.

microglia was attenuated and the morphology of microglia backed to small cell body possessed long thin branches following ICS II treatment.

\section{ICS II Attenuated A $\beta$-Induced Increase of the Expression of Pro-inflammatory Cytokines in the Hippocampus}

We then explored whether ICS II affected the generalized pro-inflammatory response from glia. The pro-inflammatory cytokines were assessed by detecting mRNA and protein expression of COX-2, IL- $1 \beta$, TNF- $\alpha$ and iNOS via real time RTPCR and Western blot, respectively. $A \beta$ injection dramatically enhanced the expression levels of IL-1 $\beta$, COX-2, TNF- $\alpha$ and iNOS mRNA, which were 3.09-, 1.89-, 1.69-, and 2.14-fold higher than those of the sham group [IL-1 $\beta$ : $F(3,20)=7.303$, $P=0.002$; COX-2: $F(3,18)=6.115, P=0.005$; TNF$\alpha: F(3,20)=5.473, P=0.007 ;$ iNOS: $F(3,20)=5.776$, $P=0.005$, Figures 7A-D], while treatment with ICS II decreased the mRNA expression of these selected genes $(P<0.05$, $0.05,0.01,0.05$, respectively). Consistent with the mRNA
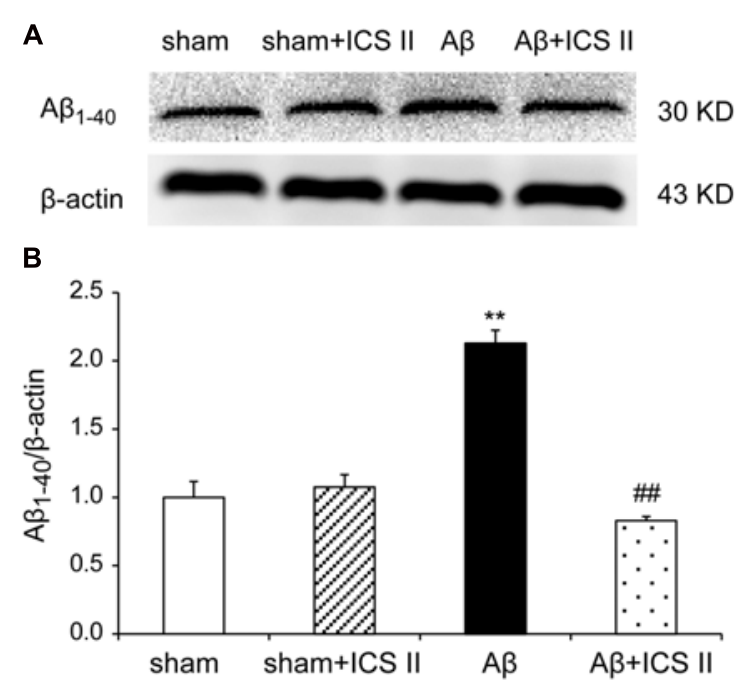

FIGURE 5 | Icariside II inhibited $A \beta_{1-40}$ levels in the hippocampus of A $\beta_{25-35}$-induced rats. $A \beta_{1-40}$ levels were examined by Western blot. (A) The antibody-reactive band of the $A \beta_{1-40}$. (B) Quantitative analysis of $A \beta_{1-40}$ levels. Data were expressed as mean $\pm \operatorname{SEM}(n=3)$. ${ }^{*} P<0.01$ vs. sham; ${ }^{\#} P<0.01$ vs. A $\beta$ alone.

expression, injection of $A \beta_{25-35}$ dramatically increased the protein expression levels of IL-1 $\beta$, COX-2, TNF- $\alpha$ and iNOS

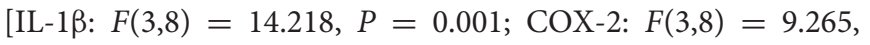
$P=0.006$; TNF- $\alpha: F(3,8)=17.558, P=0.001$; iNOS: $F(3,8)=10.624, P=0.004$, Figure 8]. ICS II treatment inhibited the expressions of the above proteins compared with the $A \beta$ group $(P<0.01,0.05,0.01,0.01)$. These data demonstrated that ICS II inhibited the overexpression of inflammatory factors induced by $\mathrm{A} \beta_{25-35}$.

\section{ICS II Repressed the Activation of Apoptotic Signaling in the Hippocampus}

Because $A \beta_{25-35}$ lowers neuronal cell viability by increasing apoptotic activity (Yao et al., 2007), the expression of Bax, $\mathrm{Bcl}-2$, the pro-caspase- 3 and the active caspase- 3 were examined to assess whether apoptotic responses were related to the protective effect of ICS II on A $\beta$-induced neurotoxicity. As shown in Figure 9, A $\beta$ injection increased Bax and decreased $\mathrm{Bcl}-2$ and thus enhanced the ratio of Bax to Bcl-2 $[F(3,8)=19.308, P=0.001]$ in the hippocampus as compared to sham group; these effects were significantly reversed by $20 \mathrm{mg} / \mathrm{kg}$ ICS II treatment $(P<0.01)$. Meanwhile, $\mathrm{A} \beta_{25-35}$ treatment reduced procaspase-3 level $[F(3,8)=11.180, P=0.003]$, and ICS II marked reversed the reduction compared with the model group $(P<0.05$, Figures 10A,B $)$. Moreover, the activation of caspase-3 was significantly ameliorated by ICS II treatment $[F(3,8)=18.860, P=0.001](P<0.01$, Figure 10C $)$. Taken together, the above findings indicated that ICS II suppressed the $A \beta_{25-35}$-induced activation of apoptotic signaling in the hippocampus. 

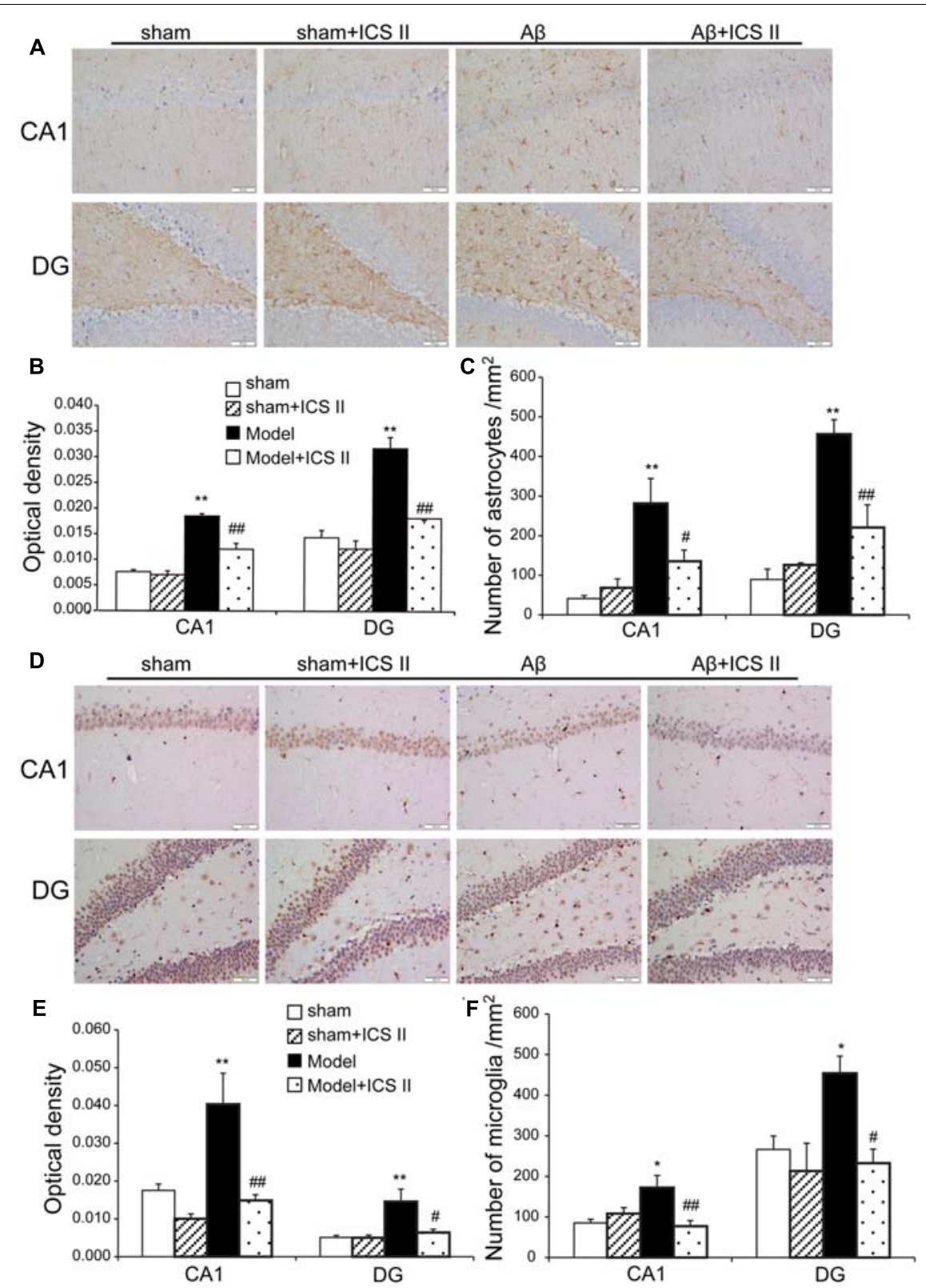

FIGURE 6 | Icariside II attenuated astrocytes and microglia response after A $\boldsymbol{\beta}$ injection. (A) GFAP immunoreactivity of hippocampus CA1 and DG region. (B) and (C) GFAP OD and number of astrocytes. (D) IBA-1 immunoreactivity of hippocampus CA1 and DG region. (E) and (F) IBA-1 OD and number of microglia. Magnification $400 \times$, scale bar $=50 \mu \mathrm{m}$. Data were expressed as mean $\pm \mathrm{SEM}, n=4 .{ }^{*} P<0.05$, ${ }^{* *} P<0.01$ vs. sham; ${ }^{\#} P<0.05$, ${ }^{\# \#} P<0.01$ vs. A $\beta$ alone.

\section{DISCUSSION}

Fibrillar $\mathrm{A} \beta$ peptides have been shown to stimulate inflammatory responses (Bona et al., 2010; Abdi et al., 2011), activate the apoptotic pathway (Clementi et al., 2005; Dean et al., 2016), increase neuronal loss (Shie et al., 2003; Thal et al., 2008), and impair spatial learning and memory (Chen et al., 2000; Wei-Na et al., 2013). A $\beta$ production and its clearance are dynamically balanced in the normal brain. $A \beta$ generates from the amyloid precursor protein (APP) and clearance through enzymatic degradation pathways, microglial phagocytosis $A \beta$ and cell autophagy, etc. (Yoon and Ahn Jo, 2012; Kruppa et al., 2013). When the balance is broken, there will be an increase in $A \beta$ levels and trigger aggregation and deposition of $A \beta$ in the brain, eventually lead to memory impairment (Christoph et al., 2003; Jun-Xia et al., 2013). The $A \beta$ peptides of 40 and 42 amino acids are prominent species in the senile plaques of patients, where $A \beta_{1-40}$ is more abundant, $A \beta_{1-42}$ shows stronger neurotoxicity. However, $A \beta_{25-35}$ is also a toxic fragment of the full-length $A \beta$ peptides and it has been demonstrated that $A \beta_{1-42}$ and the $A \beta_{25-35}$ peptides induce neural injury in a similar pattern and $A \beta_{25-35}$ is a convenient tool for the investigation of 

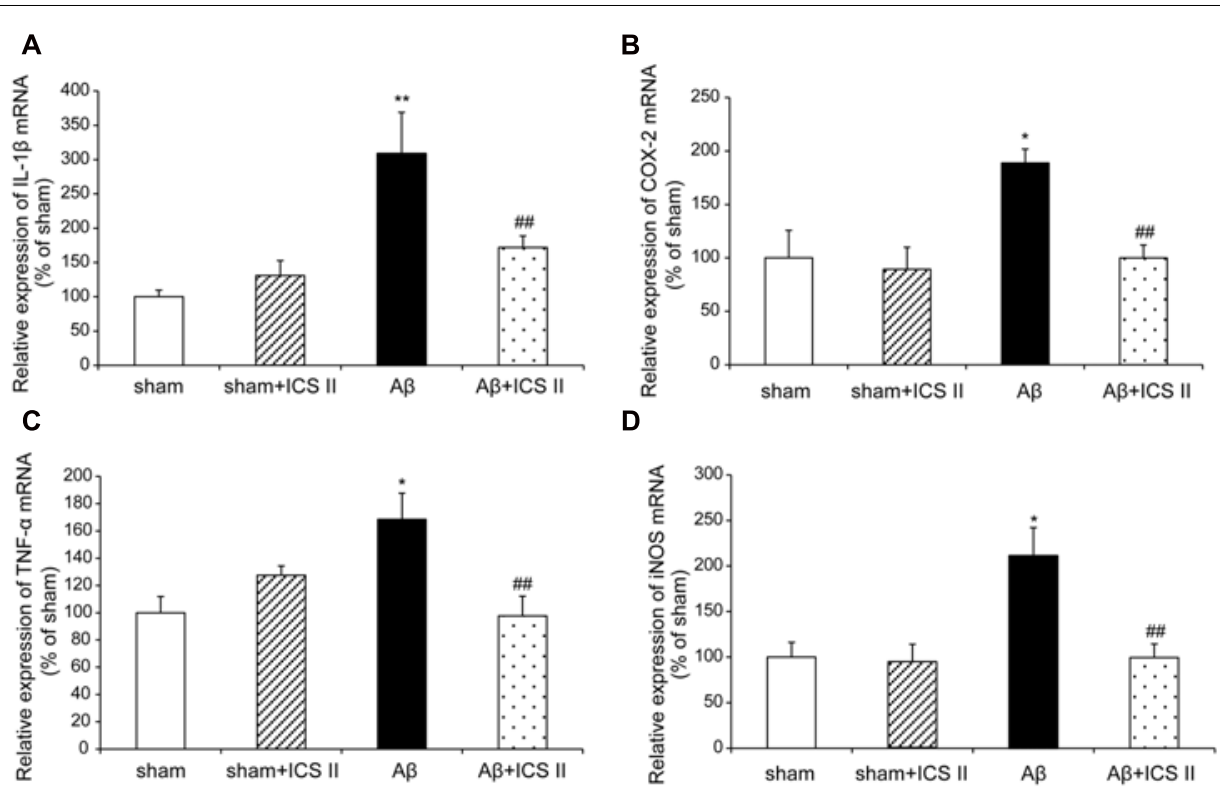

FIGURE 7 | Icariside II decreased the mRNA expression of TNF- $\alpha$, IL-1 $\beta$, COX-2, and iNOS after A $\beta$ injection. The expression of TNF- $\alpha$, IL-1 $\beta$, COX-2, and iNOS mRNA was examined by real time RT-PCR. (A) TNF- $\alpha$ mRNA; (B) IL-1 $\beta$ mRNA; (C) COX-2 mRNA; (D) iNOS mRNA. Data were expressed as mean \pm SEM $(n=6) .{ }^{*} P<0.05,{ }^{* *} P<0.01$ vs. sham; ${ }^{\#} P<0.01$ vs. $A \beta$ alone.

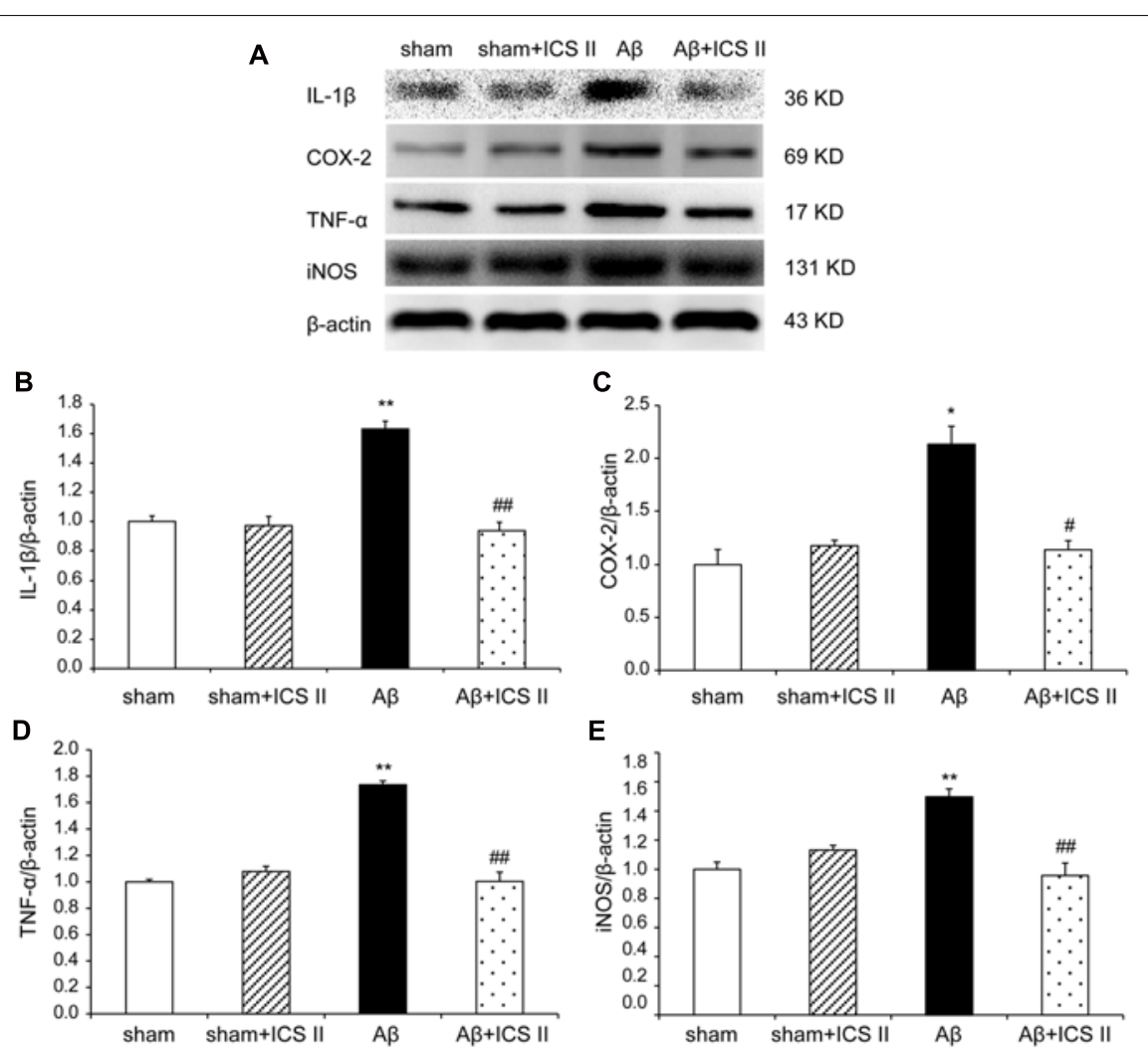

FIGURE 8 | Icariside II prevented the protein expression of TNF- $\alpha$, IL-1 $\beta$, COX-2, and iNOS after A $\beta$ injection. The expressions of TNF- $\alpha$, IL-1 $\beta$, COX-2, and iNOS protein were detected by Western blot analysis. (A) The antibody-reactive band of the TNF- $\alpha, I L-1 \beta$, COX-2, and iNOS, respectively. (B) Quantitative analysis of TNF- $\alpha$ protein; (C) Quantitative analysis of IL-1 $\beta$ protein; (D) Quantitative analysis of COX-2 protein; (E) Quantitative analysis of iNOS protein. The relative OD was normalized to $\beta$-actin. Data presented as mean \pm SEM, $n=3$. ${ }^{*} P<0.05,{ }^{*} P<0.01$ vs. sham; ${ }^{*} P<0.05$, ${ }^{\# \#} P<0.01$ vs. A $\beta$ alone. 


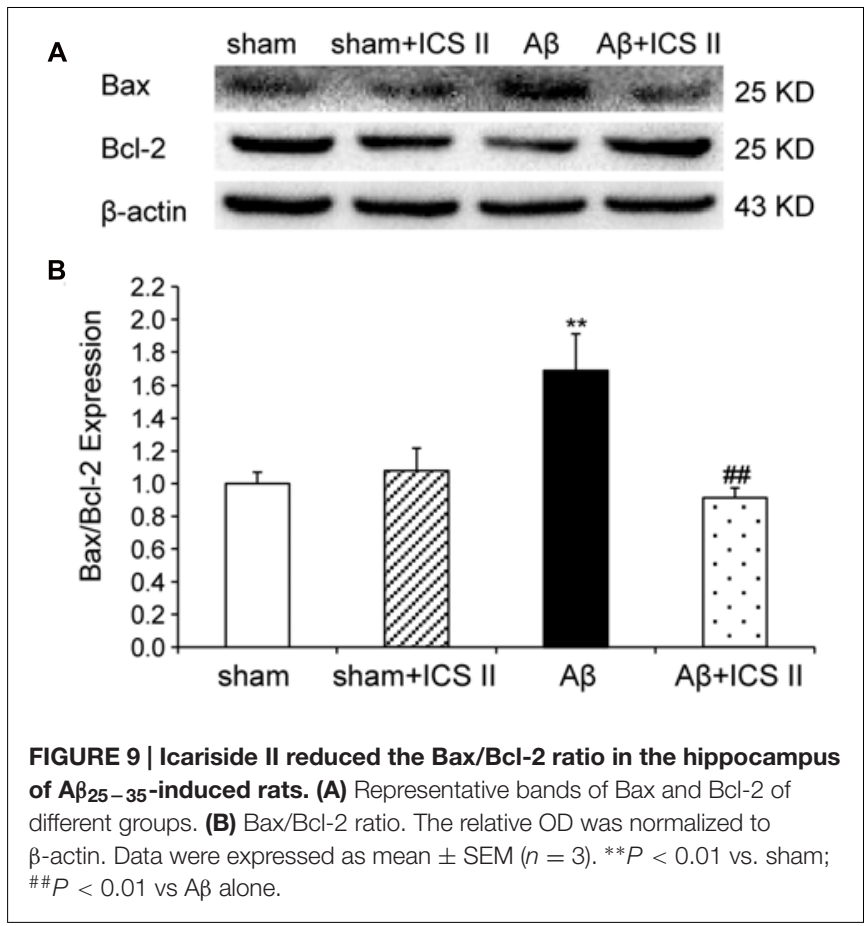

neurotoxic mechanisms involved in AD (Miao et al., 2008; Frozza et al., 2009). Hence in the present study, we also used $\mathrm{A} \beta_{25-35}$ to mimic the pathology and symptoms of $\mathrm{AD}$, and revealed that bilateral $A \beta_{25-35}$ injection into rat's hippocampi could induce learning and memory deficits. CA1 subfield of the hippocampus is the most damaged area in the brain of rats received hippocampal injection of $A \beta_{25-35}$ (Stepanichev et al., 2004). The present study consistently demonstrated that neuronal degeneration and death were evident in the CA1 region of the hippocampus of $\mathrm{A} \beta_{25-35}$-induced rats (Supplementary Figures 1-3).
Icariside II and icariin are the two major active ingredients of Herba Epimedii with close structural relationship, icariin has been reported as the most valuable compound of Epimedii to be developed to a promising neuroprotective drug treating $\mathrm{AD}$, ischemia and vascular dementia (VD) (Urano and Tohda, 2010; Jin et al., 2014; Li et al., 2014). ICS II is one of the metabolites of icariin and is widely reported as a broad-spectrum anticancer agent in recent years (Cai et al., 2011; Arief et al., 2015). Our previous studies showed that ICS II has neuroprotective effects during cerebral ischemia-reperfusion via inflammatory inhibition (Deng et al., 2016). Interestingly, the present study demonstrated administration of ICS II at the dose of $20 \mathrm{mg} / \mathrm{kg}$ markedly ameliorated the cognitive deficits and neuronal damage in the $A \beta_{25-35}$ rats. That is to say, in addition to anti-cancer effects, ICS II also showed beneficial neuroprotective effects. It has been proposed that icariin could decrease the generation of endogenous $A \beta$ in hippocampus of rats induced by exogenous injection of $A \beta_{25-35}$. In the present study, the level of $A \beta_{1-40}$ in the hippocampus was significantly higher in the $A \beta_{25-35^{-}}$ induced rats than vehicle-treated rats. However, the contents of $\mathrm{A} \beta_{1-40}$ were reduced after treatment of ICS II in $\mathrm{A} \beta_{25-35}$ rats, indicating ICS II might exert the neuroprotective effects in a similar manner with icariin.

Neuroinflammation contributes to the pathogenesis of numerous neurodegenerative diseases, including AD (Eikelenboom et al., 2010; Reale et al., 2010). Injection of $\mathrm{A} \beta$ triggers activation of microglia and astrocytes, which can release inflammatory cytokines and mediators (Matsuoka et al., 2001; Sastre et al., 2006). In the brains of AD, elevated levels of IL- $1 \beta$ and TNF- $\alpha$ suppress phagocytosis of $A \beta$ thereby impeding efficient plaque removal by resident microglia, which in turn augments the inflammatory response and formation of $\mathrm{A} \beta$ (Tuppo and Arias, 2005; Morales et al., 2010). Several studies have shown that COX-2 was overexpressed in $\mathrm{AD}$ rat brain induced by $A \beta_{25-35}$ and cerebrospinal fluid of $\mathrm{AD}$ patients (Minghetti, 2004; Cheng et al., 2006). Similarly, A $\beta$ injection

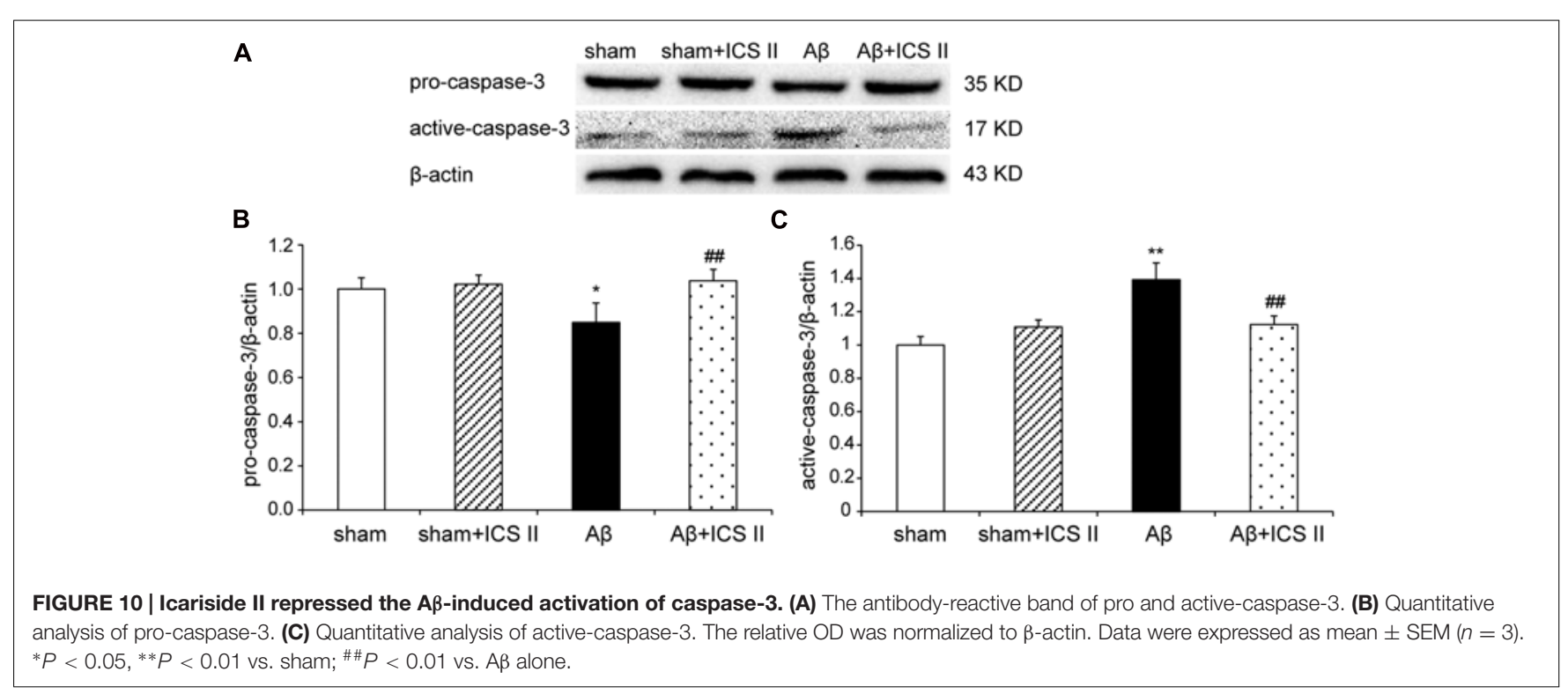


increases the expression of iNOS (Huang et al., 2011), suggesting that iNOS is a mediator of the inflammatory cascade of AD. The present study demonstrated that $A \beta_{25-35}$ injection into the hippocampus activated microglia and astrocytes and then enhanced the expression of TNF- $\alpha$, IL-1 $\beta$, COX-2, and iNOS, accompanied with an elevated endogenous $\mathrm{A} \beta$ level. Part of the reason may lie in that exogenous injection of $A \beta_{25-35}$ initiates chronic inflammation response. Chronic inflammation inhibits the activation of phagocytic machinery and affects the ability of microglia to mount a phagocytic response, thereby inhibiting clearance of $A \beta$ from microglia (Kruppa et al., 2013), and then break the balance of $A \beta$ production and degradation, which in turn lead to a generation of endogenous $A \beta$. However, the $\mathrm{A} \beta$-induced neuroinflammatory responses were largely attenuated by ICS II treatment, which is consistent with our previous findings that administration with ICS II suppression the level of $A \beta$ and inhibition of inflammation in streptozotocin (STZ)-induced rats (Yin et al., 2016). Therefore it is postulated that ICS II might exhibit a neuroprotective effect by reducing $A \beta$ concentration and suppressing the neuroinflammatory response in the hippocampus, thus preventing cell death and improving spatial learning.

Biochemical and morphological evidences of in vitro and in vivo studies have confirmed that apoptotic pathway is involved in the pathogenesis of $\mathrm{AD}$ (LeBlanc, 2005). Given the fact that hippocampus neuronal apoptosis is one of the major causes of memory loss accompanied by neurodegeneration (Mattson, 2000), cell apoptosis was further investigated. TUNEL assay displayed a significant number of TUNEL positive cells in the hippocampus of $A \beta_{25-35}$-treated animals. In agreement with the effect of neuroprotection, ICS II treatment significantly decreased the apoptotic cells in $A \beta_{25-35}$ treated rats. Various molecules have been found to participate in the mechanism of apoptosis, and the Bcl-2 family members are the most studied molecules in the regulation of apoptosis (Kitamura et al., 1998; Czabotar et al., 2014). Bcl-2 is an anti-apoptotic member of Bcl-2 family and Bax is a pro-apoptotic member working in a manner opposite to that of $\mathrm{Bcl}-2$. The ratio of $\mathrm{Bax} / \mathrm{Bcl}-2$ has been considered a critical factor to determine cell survival and death. Microinfusions of $A \beta_{25-35}$ down-regulated Bcl-2 and upregulated $\mathrm{Bax}$, leading to the elevation of the $\mathrm{Bax} / \mathrm{Bcl}-2$ ratio have been widely reported. Our results are in agreement with previous studies indicating that $\mathrm{Bcl}-2$ family proteins regulate apoptosis following $\mathrm{A} \beta$ insult and further demonstrated that ICS II treatment attenuated the hippocampal neuronal apoptosis by decreasing the ratio of $\mathrm{Bax} / \mathrm{Bcl}-2$. Moreover, intracellular apoptotic cascade including caspases family can be triggered which leads to the increases in apoptotic responses under $A \beta$ toxicity (Louneva et al., 2008). The present results provided additional data showing that intracerebral injection of $A \beta_{25-35}$ decreased the level of pro-caspase-3 and increased the level of active-caspase- 3 in the hippocampus. However, ICS II markedly inhibited the activation of caspase- 3 in $A \beta$-induced rats. Taken together, these data suggest that ICS II might serve as a potent anti-apoptotic agent, which can inhibit the apoptotic responses induced by $\mathrm{A} \beta_{25-35}$ and produce anti-inflammatory effects.
It is well known that no matter in $\mathrm{AD}$ brain or tumor microenvironment, NF- $\kappa \mathrm{B}$ is a crucial transcriptional factor involved in apoptosis and inflammatory responses. It is reported that ICS II might prohibit cancer invasion and metastasis in inflammatory microenvironment through inactivating NF- $\kappa$ B pathway (Jie et al., 2016). Consistent with its effects on cancer, our previous study showed that ICS II protected against cerebral ischemic/reperfusion injury via inhibiting I $\mathrm{B} \alpha$ degradation and the subsequent phosphorylation of NF- $\kappa \mathrm{B}$, by which elevated levels of inflammatory cytokines are repressed (Deng et al., 2016). Thus, we speculate that the suppression of NF-kB signaling might be involved in the protective effects of ICS II on cognitive impairment and associated neuroinflammation and apoptosis. In addition, transgenic model of $\mathrm{AD}$ will be further utilized to clarify the underlying mechanisms of ICS II action on AD in more depth.

\section{CONCLUSION}

In summary, the present study demonstrates that ICS II protects against learning and memory impairments and neuronal death in the hippocampus induced by $A \beta_{25-35}$ in rats. The neuroprotective mechanisms may be attributable to the blockade of inflammation and apoptosis. These results suggest that ICS II might be a promising therapeutic agent for the treatment of $\mathrm{AD}$.

\section{AUTHOR CONTRIBUTIONS}

QG and YD developed the original idea, wrote the manuscript, and acted as guarantor. YD, KW and LL performed animal studies and behavioral experiments. YD, LZ, LH, and JZ conducted the morphology experiments. YD carried out the RTPCR. LL performed the Western Blot assay. All authors read and approved the final manuscript.

\section{FUNDING}

This work was supported by Science and Technology Innovation Talent Team of Guizhou Province (Grant No.20154023), Outstanding Youth Science and Technology Talent Capital of Guizhou Province (Grant No.201326), Guizhou Provincial Health and Family Planning Commission of Science and Technology Foundation (Grant No. gzwjkj2014-1-069), the mutual fund combined Guizhou Province with Zunyi Medical University (Grant No. LH-[2015]7533), and the Science and Technology Joint Fund of 2016 combined Zunyi Science and Technology Bureau with Zunyi Medical University (Grant No. [2016]29).

\section{SUPPLEMENTARY MATERIAL}

The Supplementary Material for this article can be found online at: http://journal.frontiersin.org/article/10.3389/fphar. 2017.00039/full\#supplementary-material 


\section{REFERENCES}

Abdi, A., Sadraie, H., Dargahi, L., Khalaj, L., and Ahmadiani, A. (2011). Apoptosis inhibition can be threatening in $A \beta$-induced neuroinflammation, through promoting cell proliferation. Neurochem. Res. 36, 39-48. doi: 10.1007/s11064010-0259-3

Alzheimer's Association (2015). 2015 Alzheimer's disease facts and figures. Alzheimers Dement. J. Alzheimers Assoc. 11, 332-384. doi: 10.1016/j.jalz.2015. 02.003

Arief, Z. M., Munshi, A. H., and Shawl, A. S. (2015). Evaluation of medicinal value of Epimedium elatum on the basis of pharmacologically active constituents, Icariin and Icariside-II. Pak. J. Pharm. Sci. 28, 1665-1669.

Bamberger, M. E., and Landreth, G. E. (2002). Inflammation, apoptosis, and Alzheimer's disease. Neuroscientist 8, 276-283. doi: 10.1177/ 10758402008003013

Barnabas James, G. (1997). Republished: the role of amyloid $\beta$ in the pathogenesis of Alzheimer's disease. J. Clin. Pathol. 378, 937-950.

Bona, D., Scapagnini, G., Candore, G., Castiglia, L., Colonna-Romano, G., Duro, G., et al. (2010). Immune-inflammatory responses and oxidative stress in Alzheimer's disease: therapeutic implications. Curr. Pharm. Des. 16, 684-691. doi: 10.2174/138161210790883769

Breitner, J. C. S., Haneuse, S. J. P. A., Walker, R., Dublin, S., Crane, P. K., Gray, S. L., et al. (2009). Risk of dementia and AD with prior exposure to NSAIDs in an elderly community-based cohort. Neurology 72, 1899-1905. doi: 10.1212/ WNL.0b013e3181a18691

Cai, W.-J., Huang, J.-H., Zhang, S.-Q., Wu, B., Kapahi, P., Zhang, X.-M., et al. (2011). Icariin and its derivative icariside II extend healthspan via insulin/IGF-1 pathway in C. elegans. PLoS ONE 6:e28835. doi: 10.1371/journal.pone.0028835

Chen, Q. S., Kagan, B. L., Hirakura, Y., and Xie, C. W. (2000). Impairment of hippocampal long-term potentiation by Alzheimer amyloid $\beta$-peptides. J. Neurosci. Res. 60, 65-72. doi: 10.1002/(SICI)1097-4547(20000401)60:1<65:: AID-JNR7<3.0.CO;2-Q

Cheng, G., Whitehead, S. N., Hachinski, V., and Cechetto, D. F. (2006). Effects of pyrrolidine dithiocarbamate on beta-amyloid (25-35)-induced inflammatory responses and memory deficits in the rat. Neurobiol. Dis. 23, 140-151. doi: 10.1016/j.nbd.2006.02.008

Christoph, H., Uwe, K., Streffer, J. R., Jay, T., Andri, S., Britta, M. T., et al. (2003). Antibodies against beta-amyloid slow cognitive decline in Alzheimer's disease. Neuron 38, 547-554. doi: 10.1016/S0896-6273(03)00294-0

Clementi, M. E., Marini, S., Coletta, M., Orsini, F., Giardina, B., and Misiti, F. (2005). $A \beta(31-35)$ and $A \beta(25-35)$ fragments of amyloid beta-protein induce cellular death through apoptotic signals: role of the redox state of methionine35. FEBS Lett. 579, 2913-2918. doi: 10.1016/j.febslet.2005.04.041

Czabotar, P. E., Lessene, G., Strasser, A., and Adams, J. M. (2014). Control of apoptosis by the BCL-2 protein family: implications for physiology and therapy. Nat. Rev. Mol. Cell Biol. 15, 49-63. doi: 10.1038/nrm3722

Dean, D. N., Pate, K. M., Moss, M. A., and Rangachari, V. (2016). Conformational dynamics of specific $A \beta$ oligomers govern their ability to replicate and induce neuronal apoptosis. Biochemistry 55, 2238-2250. doi: 10.1021/acs.biochem. 6b00161

Deng, Y., Xiong, D., Yin, C., Liu, B., Shi, J., and Gong, Q. (2016). Icariside II protects against cerebral ischemia-reperfusion injury in rats via nuclear factor$\kappa \mathrm{B}$ inhibition and peroxisome proliferator-activated receptor up-regulation. Neurochem. Int. 96, 56-61. doi: 10.1016/j.neuint.2016.02.015

Diaz, A., Limon, D., Chávez, R., Zenteno, E., and Guevara, J. (2012). Aß2535 injection into the temporal cortex induces chronic inflammation that contributes to neurodegeneration and spatial memory impairment in rats. J. Alzheimers Dis. 30, 505-522. doi: 10.3233/JAD-2012-111979

Driver, J. A. (2012). Understanding the link between cancer and neurodegeneration. J. Geriatr. Oncol. 3, 58-67. doi: 10.1016/j.jgo.2011.11.007

Eikelenboom, P., Van Exel, E., Hoozemans, J. J., Veerhuis, R., Rozemuller, A. J., and Van Gool, W. A. (2010). Neuroinflammation-an early event in both the history and pathogenesis of Alzheimer's disease. Neurodegener. Dis. 7, 38-41. doi: $10.1159 / 000283480$

Frozza, R. L., Horn, A. P., Hoppe, J. B., Simão, F., Gerhardt, D., Comiran, R. A., et al. (2009). A comparative study of $\beta$-amyloid peptides $A \beta 1-42$ and $A \beta 25-$ 35 toxicity in organotypic hippocampal slice cultures. Neurochem. Res. 34, 295-303. doi: 10.1007/s11064-008-9776-8
Gong, Q. H., Wang, Q. L., Liu, X. H., Huang, H., and Zhu, Y. Z. (2010). Hydrogen sulfide attenuates lipopolysaccharide-induced cognitive impairment: a proinflammatory pathway in rats. Pharmacol. Biochem. Behav. 96, 52-58. doi: 10.1016/j.pbb.2010.04.006

Gouras, G. K., Olsson, T. T., and Hansson, O. (2014). $\beta$-amyloid peptides and amyloid plaques in Alzheimer's Disease. J. Am. Soc. Exp. Neurother. 12, 1-9.

Huang, T.-C., Lu, K.-T., Wo, Y.-Y. P., Wu, Y.-J., and Yang, Y.-L. (2011). Resveratrol protects rats from $\mathrm{A} \beta$-induced neurotoxicity by the reduction of iNOS expression and lipid peroxidation. PLoS ONE 6:e29102. doi: 10.1371/ journal.pone.0029102

Jie, S., Liang, F., Zhong, R., Zhi, X., Li, Z., Li, C., et al. (2016). Icariside II inhibits the EMT of NSCLC cells in inflammatory microenvironment via down-regulation of Akt/NF-кB signaling pathway. Mol. Carcinog. 56, 36-48. doi: 10.1002/mc. 22471

Jin, F., Gong, Q. H., Xu, Y. S., Wang, L. N., Jin, H., Li, F., et al. (2014). Icariin, a phoshphodiesterase-5 inhibitor, improves learning and memory in APP/PS1 transgenic mice by stimulation of NO/cGMP signalling. Int. J. Neuropsychopharmacol. 17, 871-881. doi: 10.1017/S1461145713001533

Joan, V. F., Secundino, L. P., Laia, C. P., and Josep, G. O. (2013). Psychosis of Alzheimer disease: prevalence, incidence, persistence, risk factors, and mortality. Am. J. Geriatr. Psychiatry 21, 1135-1143. doi: 10.1016/j.jagp.2013.01. 051

Jun-Xia, L., Wei, Q., Wai-Ming, Y., Schwieters, C. D., Meredith, S. C., and Robert, T. (2013). Molecular structure of $\beta$-amyloid fibrils in Alzheimer's disease brain tissue. Cell 154, 1257-1268. doi: 10.1016/j.cell.2013.08.035

Kitamura, Y., Shimohama, S., Kamoshima, W., Ota, T., Matsuoka, Y., Nomura, Y., et al. (1998). ). Alteration of proteins regulating apoptosis, Bcl-2, Bcl-x, Bax, Bak, Bad, ICH-1 and CPP32, in Alzheimer's disease. Brain Res. 780, 260-269.

Kruppa, A. J., Ott, S., Chandraratna, D. S., Irving, J. A., Page, R. M., Speretta, E., et al. (2013). Suppression of $A \beta$ toxicity by puromycin-sensitive aminopeptidase is independent of its proteolytic activity. Biochim. Biophys. Acta 1832, 21152126. doi: 10.1016/j.bbadis.2013.07.019

LeBlanc, A. C. (2005). The role of apoptotic pathways in Alzheimer's disease neurodegeneration and cell death. Cur. Alzheimer Res. 2, 389-402. doi: 10.2174/ 156720505774330573

Lee, K. S., Lee, H. J., Ahn, K. S., Kim, S. H., Nam, D., Kim, D. K., et al. (2009). Cyclooxygenase-2/prostaglandin E 2 pathway mediates icariside II induced apoptosis in human PC-3 prostate cancer cells. Cancer Lett. 280, 93-100. doi: 10.1016/j.canlet.2009.02.024

Li, W., Deng, Y., Shi, J., Li, F., Liu, B., and Gong, Q. (2014). Icariin ameliorates spatial learning and memory impairments through upregulating the expressions of PPAR $\alpha$ and PGC- $1 \alpha$ protein in chronic cerebral hypoperfusion rat model. J. Zunyi Med. Univ. 37, 591-594.

Li, W.-X., Deng, Y.-Y., Li, F., Liu, B., Liu, H.-Y., Shi, J.-S., et al. (2015). Icariin, a major constituent of flavonoids from Epimedium brevicornum, protects against cognitive deficits induced by chronic brain hypoperfusion via its antiamyloidogenic effect in rats. Pharmacol. Biochem. Behav. 138, 40-48. doi: 10. 1016/j.pbb.2015.09.001

Liu, H., Deng, Y., Gao, J., Liu, Y., Shi, J., and Gong, Q. (2015). Sodium hydrosulfide attenuates beta-amyloid-induced cognitive deficits and neuroinflammation via modulation of MAPK/NF-кB pathway in rats. Curr. Alzheimer Res. 12, 673-683. doi: 10.2174/1567205012666150713102326

Louneva, N., Cohen, J. W., Han, L.-Y., Talbot, K., Wilson, R. S., Bennett, D. A., et al. (2008). Caspase-3 is enriched in postsynaptic densities and increased in Alzheimer's disease. Am. J. Pathol. 173, 1488-1495. doi: 10.2353/ajpath.2008. 080434

Matsuoka, Y., Picciano, M., Malester, B., Lafrancois, J., Zehr, C., Daeschner, J. M., et al. (2001). Inflammatory responses to amyloidosis in a transgenic mouse model of Alzheimer's disease. Am. J. Pathol. 158, 1345-1354. doi: 10.1016/ S0002-9440(10)64085-0

Mattson, M. P. (2000). Apoptosis in neurodegenerative disorders. Nat. Rev. Mol. Cell Biol. 1, 120-130. doi: 10.1038/35040009

Meng, F.-H., Li, Y.-B., Xiong, Z.-L., Jiang, Z.-M., and Li, F.-M. (2005). Osteoblastic proliferative activity of $<\mathrm{i}>$ Epimedium brevicornum $</ \mathrm{i}>$ maxim. Phytomedicine 12, 189-193. doi: 10.1016/j.phymed.2004.03.007

Miao, J., Zhang, W., Yin, R., Liu, R., Su, C., Lei, G., et al. (2008). S14GHumanin ameliorates A $\beta 25-35$-induced behavioral deficits by reducing 
neuroinflammatory responses and apoptosis in mice. Neuropeptides 42, 557567. doi: 10.1016/j.npep.2008.08.004

Minghetti, L. (2004). Cyclooxygenase-2 (COX-2) in inflammatory and degenerative brain diseases. J. Neuropathol. Exp. Neurol. 63, 901-910. doi: 10.1093/jnen/63.9.901

Morales, I., Farias, G., and Maccioni, R. B. (2010). Neuroimmunomodulation in the pathogenesis of Alzheimer's disease. Neuroimmunomodulation 17, 202-204. doi: $10.1159 / 000258724$

Nie, J., Luo, Y., Huang, X. N., Gong, Q. H., Wu, Q., and Shi, J. S. (2010). Icariin inhibits beta-amyloid peptide segment 25-35 induced expression of betasecretase in rat hippocampus. Eur. J. Pharmacol. 626, 213-218. doi: 10.1016/j. ejphar.2009.09.039

Paula, A., Cunha, R. A., and Catarina, O. (2010). Neuroinflammation, oxidative stress and the pathogenesis of Alzheimer's disease. Curr. Pharm. Des. 16, 2766-2778. doi: 10.2174/138161210793176572

Pike, C. J., Walencewicz-Wasserman, A. J., Joseph, K., Cribbs, D. H., Glabe, C. G., and Cotman, C. W. (1995). Structure-activity analyses of $\beta$-amyloid peptides: contributions of the $\beta 25-35$ region to aggregation and neurotoxicity. J. Neurochem. 64, 253-265. doi: 10.1046/j.1471-4159.1995.6401 0253.x

Plunfavreau, H., Lewis, P. A., Hardy, J., Martins, L. M., and Wood, N. W. (2010). Cancer and neurodegeneration: between the devil and the deep blue sea. PloS Genet. 6:e1001257. doi: 10.1371/journal.pgen.1001257

Potter, P. E. (2010). Investigational medications for treatment of patients with Alzheimer disease. J. Am. Osteopath. Assoc. 110, S27-S36.

Reale, M., Brenner, T., Greig, N. H., Inestrosa, N., and Paleacu, D. (2010). Neuroinflammation, AD, and dementia. Int. J. Alzheimers Dis. 2010:974026. doi: 10.4061/2010/974026

Sastre, M., Klockgether, T., and Heneka, M. T. (2006). Contribution of inflammatory processes to Alzheimer's disease: molecular mechanisms. Int. J. Dev. Neurosci. 24, 167-176. doi: 10.1016/j.ijdevneu.2005.11.014

Saur, L., Baptista, P. P. A., Senna, P. N. D., Paim, M. F., Nascimento, P. D., Ilha, J., et al. (2014). Physical exercise increases GFAP expression and induces morphological changes in hippocampal astrocytes. Brain Struct. Funct. 219, 293-302. doi: 10.1007/s00429-012-0500-8

Shie, F.-S., Leboeur, R. C., and Jin, L.-W. (2003). Early intraneuronal A $\beta$ deposition in the hippocampus of APP transgenic mice. Neuroreport 14, 123-129. doi: 10.1097/00001756-200301200-00023

Song, J., Shu, L., Zhang, Z., Tan, X., Sun, E., Jin, X., et al. (2012). Reactive oxygen species-mediated mitochondrial pathway is involved in baohuoside I-induced apoptosis in human non-small cell lung cancer. Chem. Biol. Interact. 199, 9-17. doi: 10.1016/j.cbi.2012.05.005

Srivareerat, M., Tran, T. T., Salim, S., Aleisa, A. M., and Alkadhi, K. A. (2011). Chronic nicotine restores normal $A \beta$ levels and prevents short-term memory and E-LTP impairment in A $\beta$ rat model of Alzheimer's disease. Neurobiol. Aging 32, 834-844. doi: 10.1016/j.neurobiolaging.2009.04.015

Stepanichev, M. Y., Zdobnova, I. M., Zarubenko, I. I., Moiseeva, Y. V., Lazareva, N. A., Onufriev, M. V., et al. (2004). Amyloid- $\beta(25-35)$-induced memory impairments correlate with cell loss in rat hippocampus. Physiol. Behav. 80, 647-655. doi: 10.1016/j.physbeh.2003.11.003

Suh, Y. H., and Checler, F. (2002). Amyloid precursor protein, presenilins, and alpha-synuclein: molecular pathogenesis and pharmacological applications in Alzheimer's disease. Pharmacol. Rev. 54, 469-525. doi: 10.1124/pr.54.3.469

Sze, S. C. W., Tong, Y., Ng, T. B., Cheng, C. L. Y., and Cheung, H. P. (2010). Herba Epimedii: anti-oxidative properties and its medical implications. Molecules 15, 7861-7870. doi: 10.3390/molecules15117861
Thal, D. R., Griffin, W. S. T., and Braak, H. (2008). Parenchymal and vascular $\mathrm{A} \beta$-deposition and its effects on the degeneration of neurons and cognition in Alzheimer's disease. J. Cell Mol. Med. 12, 1848-1862. doi: 10.1111/j.1582-4934. 2008.00411.x

Townsend, K. P., and Domenico, P. (2005). Novel therapeutic opportunities for Alzheimer's disease: focus on nonsteroidal anti-inflammatory drugs. FASEB J. 19, 1592-1601. doi: 10.1096/fj.04-3620rev

Tuppo, E. E., and Arias, H. R. (2005). The role of inflammation in Alzheimer's disease. Int. J. Biochem. Cell Biol. 37, 289-305. doi: 10.1016/j.biocel.2004.07.009

Urano, T., and Tohda, C. (2010). Icariin improves memory impairment in Alzheimer's disease model mice (5xFAD) and attenuates amyloid $\beta$-induced neurite atrophy. Phytother. Res. 24, 1658-1663. doi: 10.1002/ptr.3183

Vorhees, C. V., and Williams, M. T. (2005). Morris water maze: procedures for assessing spatial and related forms of learning and memory. Nat. Protoc. 1, 848-858. doi: 10.1038/nprot.2006.116

Wang, C., Yang, X. M., Zhuo, Y. Y., Zhou, H., Lin, H. B., Cheng, Y. F., et al. (2012). The phosphodiesterase 4 inhibitor rolipram reverses $A \beta$-induced cognitive impairment and neuroinflammatory and apoptotic responses in rats. Int. J. Neuropsychopharmacol. 15, 749-766. doi: 10.1017/S1461145711000836

Wei-Na, H., Christian, H. L., Li, Y., Wei, Y., Xiao-Hui, W., Mei-Na, W., et al. (2013). Liraglutide protects against amyloid- $\beta$ protein-induced impairment of spatial learning and memory in rats. Neurobiol. Aging 34, 576-588. doi: 10.1016/ j.neurobiolaging.2012.04.009

Wu, J., Song, T., Liu, S., Li, X., Li, G., and Xu, J. (2015). Icariside II inhibits cell proliferation and induces cell cycle arrest through the ROS-p38-p53 signaling pathway in A375 human melanoma cells. Mol. Med. Rep. 11, 410-416. doi: 10.3892/mmr.2014.2701

Xiao, P.-G., Xing, S.-T., and Wang, L.-W. (1993). Immunological aspects of Chinese medicinal plants as antiageing drugs. J. Ethnopharmacol. 38, 159-165. doi: 10.1016/0378-8741(93)90012-T

Yan, B. Y., Pan, C. S., Mao, X. W., Yang, L., Liu, Y. Y., Yan, L., et al. (2014). Icariside II improves cerebral microcirculatory disturbance and alleviates hippocampal injury in gerbils after ischemia-reperfusion. Brain Res. 1573, 63-73. doi: 10. 1016/j.brainres.2014.05.023

Yao, M., Nguyen, T., and Pike, C. J. (2007). Estrogen regulates Bcl-w and bim expression: role in protection against $\beta$-amyloid peptide-induced neuronal death. J. Neurosci. 27, 1422-1433. doi: 10.1523/JNEUROSCI.2382-06.2007

Yin, C., Deng, Y., Gao, J., Li, X., Liu, Y., and Gong, Q. (2016). Icariside II, a novel phosphodiesterase-5 inhibitor, attenuates streptozotocin-induced cognitive deficits in rats. Neuroscience 328, 69-79. doi: 10.1016/j.neuroscience. 2016.04.022

Yoon, S. S., and Ahn Jo, S. (2012). Mechanisms of amyloid- $\beta$ peptide clearance: potential therapeutic targets for Alzheimer's Disease. Biomol. Ther. (Seoul) 20, 245-255. doi: 10.4062/biomolther.2012.20.3.245

Conflict of Interest Statement: The authors declare that the research was conducted in the absence of any commercial or financial relationships that could be construed as a potential conflict of interest.

Copyright (c) 2017 Deng, Long, Wang, Zhou, Zeng, He and Gong. This is an openaccess article distributed under the terms of the Creative Commons Attribution License (CC BY). The use, distribution or reproduction in other forums is permitted, provided the original author(s) or licensor are credited and that the original publication in this journal is cited, in accordance with accepted academic practice. No use, distribution or reproduction is permitted which does not comply with these terms. 